Article

\title{
Bubble Clouds in Coastal Waters and Their Role in Air-Water Gas Exchange of $\mathrm{CO}_{2}$
}

\author{
Joseph R. Crosswell ${ }^{1,2}$
}

1 University of Technology Sydney, PO Box 123, Broadway, NSW 2007, Australia; E-Mail: Joseph.Crosswell@uts.edu.au; Tel.: +61-2-9514-8334

2 Department of Environmental Sciences and Engineering, University of North Carolina at Chapel Hill, 66 Rosenau Hall, CB \#7431, Chapel Hill, NC 27599, USA

Academic Editor: Robert C. Upstill-Goddard

Received: 3 July 2015 / Accepted: 3 August 2015 / Published: 12 August 2015

\begin{abstract}
Bubbles generated by breaking waves can drive significant gas exchange between the ocean and atmosphere, but the role of bubble-mediated gas transfer in estuaries is unknown. Here, backscatter data from 41 acoustic Doppler current profiler stations was analyzed to assess subsurface bubble distributions in nine estuaries along the U.S. East and Gulf Coast. Wind speed, wind direction, and current velocity were the dominant controls on bubble entrainment, but the relative importance of these physical drivers depended on local geomorphology. Bubble entrainment in high-current or shallow, long-fetch estuaries began at wind speeds $<5 \mathrm{~m} \mathrm{~s}^{-1}$. In deep or fetch-limited estuaries, bubble entrainment was less frequent and generally began at higher wind speeds. Data observed during several storms suggests that episodic bubble-driven gas exchange may be an important component of annual $\mathrm{CO}_{2}$ fluxes in large, shallow estuaries but would be less significant in other coastal systems.
\end{abstract}

Keywords: gas exchange; bubbles; storms; $\mathrm{CO}_{2}$; air-sea flux

\section{Introduction}

Air-water gas exchange is an important component of global biogeochemical cycling, and extensive research has focused on measuring gas transfer between the ocean and atmosphere [1,2]. Much less is known about air-water gas exchange in estuaries and coastal waters, despite their significance to global 
and regional carbon budgets [3-5]. The underlying mechanisms of gas transfer are influenced by a range of environmental factors that vary between ocean and coastal waters as well as among different types of coastal systems [6,7]. Nevertheless, after correcting for gas solubility, wind speed is the only environmental forcing in many widely-used gas transfer dependencies, e.g., [1,8-13]. Single-variable parameterizations contribute to large uncertainty in air-water flux estimates for $\mathrm{CO}_{2}$ and other trace gasses because they overlook important environmental controls on gas exchange [1,14-18].

Gas exchange between the ocean and atmosphere is a function of the gas transfer velocity and the gradient across the air-water interface. The gas transfer velocity is regulated by boundary layer interactions which can be separated into three fundamental components: (1) smooth-surface exchange in the absence of waves; (2) rough-surface exchange in the presence of non-breaking waves; and (3) bubble-mediated exchange driven primarily by breaking waves [1,19]. Wave breaking increases turbulence while generating bubbles that experience enhanced gas transfer from surface tension and hydrostatic forcing. Bubbles can also drive gas exchange through buoyancy effects, bubble dissolution, and aerosol production upon bursting. The importance of these processes in air-water exchange is well-recognized but is not well understood due to the difficulty of measuring bubble-mediated fluxes [9,20-23].

Attempts to quantify the role of bubbles in oceanic gas exchange have yielded widely-variable dependencies on wind speed and wave spectra that span four orders of magnitude [21-27]. Uncertainties among these parameterizations are amplified in coastal waters by several compounding factors. Surface turbulence and wave breaking exhibit large spatial heterogeneity linked to wind speed, fetch, water currents, water-column stratification, coastal topography, water quality, and bathymetry [7,14,25,28-32]. The lack of constraint at high wind speeds is another major obstacle in estimating air-water fluxes [14]. For example, the range of wind speeds represented in estuary gas-transfer data is approximately half the range of oceanic data, even though storms are frequent in land-ocean convergence zones [33,34]. The influence of local controls on bubble entrainment and implications for gas exchange have yet to be examined at a scale that compares different coastal system types.

Acoustic sensing methods have been frequently used to study subsurface bubble plumes formed by breaking waves in deep and open-ocean waters [35-48]. Recently, Vagle et al. [49] and Wang et al. [50] deployed acoustic instruments in continental shelf waters to characterize the static bubble cloud that persists below the water surface due to wave breaking during storms. These studies provided new data on bubble plumes that are key to understanding gas-transfer velocities at high wind speeds. Here, I employ similar methods at a course but broad scale to examine the environmental controls on bubble entrainment in nine coastal systems along the U.S. East and Gulf Coast (Figure 1, Table 1). This study stemmed from prior research that was aimed at quantifying air-water $\mathrm{CO}_{2}$ fluxes during storms, and accordingly, implications for gas exchange are discussed with specific consideration of $\mathrm{CO}_{2}$.

\section{Materials and Methods}

\subsection{Acoustic Measurement of Bubbles}

Breaking waves generate plumes of varying bubble concentration, size distribution, and penetration depth [51-54]. Smaller bubbles have a lower buoyancy and thus longer average lifetime than larger 
bubbles and are more susceptible to sustained entrainment by subsurface turbulence. At higher wave breaking frequencies, bubble plumes overlap to form a continuous bubble cloud that extends to a depth determined by the interaction of local physical forces. Acoustic methods of observing these plume characteristics are based on the assumption of selective attenuation and sound scattering by resonant bubbles in water. The different scales at which these processes can be studied require specific observational methods. Multi-frequency instruments are required to determine bubble size distribution and void fraction due to size-dependent resonance frequencies, while direct resolution of individual waves and bubble plumes requires high-performance, high-frequency SONAR that are specifically designed for the task $[48,49,55]$. The cost and operational demands of these instruments often restrict the extent and time of deployment. This study employs a simplified, low-fidelity approach to estimate mean bubble cloud depth using a large, existing dataset from acoustic Doppler current profilers (ADCPs).

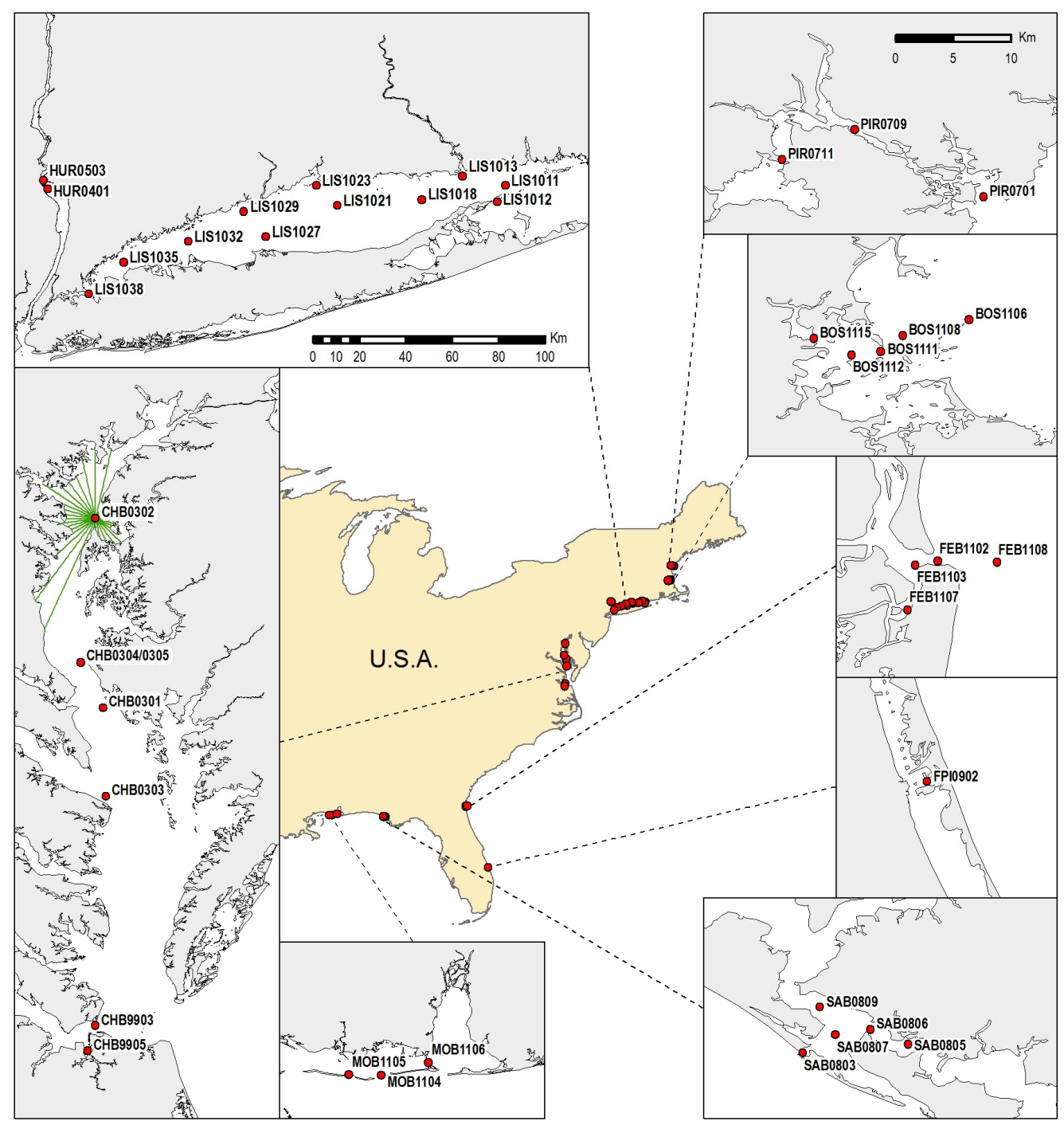

Figure 1. Acoustic Doppler current profilers (ADCP) deployment locations showing National Oceanic and Atmospheric Administration Center for Operational Oceanographic Products and Services, USA (NOAA CO-OPS) station names in large systems (left scale) and small systems (right scale). $10^{\circ}$ lines were projected from all stations (shown here at 
CHB0302 only) for estimation of fetch. Station-specific geomorphology features are listed in Table 1.

Table 1. Geomorphology features of ADCP stations.

\begin{tabular}{|c|c|c|}
\hline Station & Location & Site Description \\
\hline BOS1106 & \multirow{5}{*}{ Boston Harbor } & Shoal surrounded by deeper water \\
\hline BOS1108 & & \multirow{4}{*}{ Dredged channel surrounded by shallower water } \\
\hline BOS1111 & & \\
\hline BOS1112 & & \\
\hline BOS1115 & & \\
\hline CHB0301 & \multirow{5}{*}{ Chesapeake Bay } & \multirow{5}{*}{ Shallow, variable fetch limitation } \\
\hline CHB0302 & & \\
\hline CHB0303 & & \\
\hline CHB0304 & & \\
\hline CHB0305 & & \\
\hline CHB9903 & \multirow{2}{*}{ Norfolk Harbor } & \multirow{2}{*}{ Deep, fetch limited } \\
\hline CHB9905 & & \\
\hline FEB1102 & Fernandina Beach Harbor & Shallow, fetch limited \\
\hline FEB1103 & \multirow{2}{*}{ Cumberland Sound } & \multirow{3}{*}{$\begin{array}{l}\text { At estuary inlet bordered by jetty } \\
\text { At jetty point, open to ocean }\end{array}$} \\
\hline FEB1107 & & \\
\hline FEB1108 & Fernandina Beach & \\
\hline FPI0902 & Indian River Lagoon Inlet & At estuary inlet bordered by jetty \\
\hline $\begin{array}{l}\text { HUR0401 } \\
\text { HUR0503 }\end{array}$ & Hudson River Estuary & Fetch-limited except along river axis, steep topography \\
\hline LIS1011 & \multirow{11}{*}{ Long Island Sound } & Deep, broad inlet \\
\hline LIS1012 & & Deep, narrow inlet \\
\hline LIS1013 & & Surrounded by shoals and jetty \\
\hline LIS1018 & & \\
\hline LIS1021 & & Deep, long fetch \\
\hline LIS1023 & & Fetch limited to north by jetty, long fetch to south \\
\hline LIS1027 & & Deep, open water \\
\hline LIS1029 & & Shoal surrounded by deep water \\
\hline LIS1032 & & Deen long fetch \\
\hline LIS1035 & & \\
\hline LIS1038 & & Deep, fetch limited \\
\hline MOB1104 & \multirow{3}{*}{ Mobile Bay } & \multirow{3}{*}{$\begin{array}{l}\text { Natural estuary inlet bordered by shoals } \\
\text { In channel between bridge piles }\end{array}$} \\
\hline MOB1105 & & \\
\hline MOB1106 & & \\
\hline PIR0701 & Portsmouth Harbor & Deep, broad channel in harbor \\
\hline PIR0709 & Piscataqua River & Deep, narrow channel \\
\hline PIR0711 & Great Bay & Deep, narrow channel in Great Bay \\
\hline SAB0803 & \multirow{5}{*}{ St. Andrew's Bay } & At estuary inlet bordered by jetty and shoreline \\
\hline SAB0805 & & \\
\hline SAB0806 & & \multirow{3}{*}{ Variable fetch limitation } \\
\hline SAB0807 & & \\
\hline SAB0809 & & \\
\hline
\end{tabular}




\subsection{ADCP Observations}

Echo-intensity data from 41 bottom-mounted, single-frequency ADCPs (Teledyne RD Instruments, Poway, CA, USA) were obtained by request from the National Oceanic and Atmospheric Administration Center for Operational Oceanographic Products and Services, USA (NOAA CO-OPS) (Figure 1, Table 1). Ancillary data for each station was obtained through the NOAA public data access portal [56]. ADCPs were deployed as part of current surveys occurring between 1999 and 2011. In following sections, stations are either referenced individually by the station name defined in the NOAA CO-OPS database, or multiple stations are referenced as a group by listing only the common station letters, e.g., CHB99 would represent both CHB9903 and CHB9905 (Figure 1, Table 1).

The frequency and depth bin sizes for internal averaging of data varied from 300 to $1200 \mathrm{kHz}$ and 0.35 to $2.0 \mathrm{~m}$, respectively, depending upon the depth at the deployment site (Table 2). Echo intensity profiles for all ADCPs were recorded as average ensembles of 345 pings over 6-minute intervals along with temperature and pressure sensor data over each interval. Vertical profiles of relative backscatter in decibels $(\mathrm{dB})$ were determined from raw data following the methods of Gostiaux and van Haren [57] and Rossby et al. [58].

The mean depth of the bubble cloud for each ensemble was defined as the depth at which the backscatter profile dropped below a site-specific noise threshold (Figures 2 and 3). For simplicity, I henceforth refer to the mean bubble cloud depth as "bubble depth". The backscatter threshold was determined based on ambient noise levels in the water column when wind speeds were in the lower 10th percentile of the study period distribution. Only backscatter data from $10 \%$ below the surface to $50 \%$ of the total depth were used to estimate the threshold value, as this excluded potential surface interference while still representing the higher noise level of the upper water column. The threshold was then set at the mean plus three standard deviations of the low-wind backscatter data.

Side-Lobe Interference

ADCP data from the top $6 \%$ to $10 \%$ of the water column are normally rejected when calculating current velocities because the side-lobe echo off the air-water surface may not be adequately suppressed. The resulting signal appears as a peak in the backscatter intensity at a depth proportional to the transducer angle to vertical (Figure 2). However, it is unnecessary to exclude all near-surface bins if the goal is to resolve the one-dimensional depth of threshold exceedance. Here, the effect of instrument tilt was exploited to suppress the relative influence of bins that were contaminated by the side-lobe signal. The depth of the side lobe signal was determined based on geometric corrections in Equation 1:

$$
\begin{aligned}
& \text { Beam 1: } z_{s l 1}=z_{0}-z_{0} \cos \left(-\sin \theta_{r} \sin \theta_{0}+\cos \theta_{0} \sqrt{1-\sin ^{2} \theta_{r}-\sin ^{2} \theta_{p}}\right) \\
& \text { Beam 2: } z_{s l 2}=z_{0}-z_{0} \cos \left(+\sin \theta_{r} \sin \theta_{0}+\cos \theta_{0} \sqrt{1-\sin ^{2} \theta_{r}-\sin ^{2} \theta_{p}}\right) \\
& \text { Beam 3: } z_{s l 3}=z_{0}-z_{0} \cos \left(+\sin \theta_{p} \sin \theta_{0}+\cos \theta_{0} \sqrt{1-\sin ^{2} \theta_{r}-\sin ^{2} \theta_{p}}\right) \\
& \text { Beam 4: } z_{s l 4}=z_{0}-z_{0} \cos \left(-\sin \theta_{p} \sin \theta_{0}+\cos \theta_{0} \sqrt{1-\sin ^{2} \theta_{r}-\sin ^{2} \theta_{p}}\right)
\end{aligned}
$$


where $z_{s l}$ is the beam-specific depth of the side-lobe peak, $z_{0}$ is the distance from the transducer to the surface, and $\theta_{0}, \theta_{r}$, and $\theta_{p}$ are the transducer configuration angle, the roll angle, and the pitch angle to vertical, respectively. Finally, the four beams were integrated into a single vertical backscatter profile using the MATLAB R2012b spaps() smoothing function with each bin value weighted proportional to the side-lobe peak depth (Equation 2) on a primary pass and proportional to the default trapezoidal rule approximation an a secondary pass.

$$
S v_{w, i}=S v_{o, i}\left(\exp \left(z_{s l} / z_{i}\right)^{-1}+0.001\right)
$$

where $S v_{w, i}$ is the weighted backscatter, $S v_{o, i}$ is the observed backscatter, and $z_{i}$ is the depth of bin $i$. The constant term in Equation 2 keeps data at $z_{s l}$ from being entirely removed before the second filter pass. Figure 2 shows examples of smoothed profiles for low and high-frequency ADCPs.
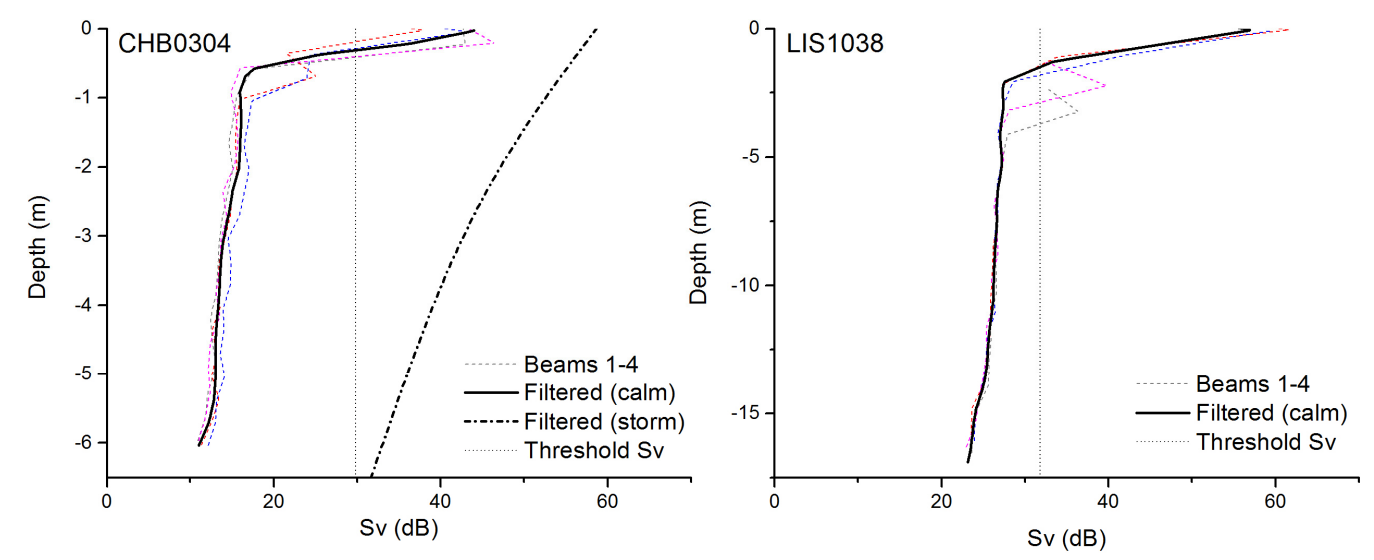

Figure 2. Vertical backscatter profiles for $1200 \mathrm{kHz}$ (CHB0304) and $600 \mathrm{kHz}$ (LIS1038) ADCPs. Beam depths were geometrically corrected and filtered to remove side lobe signals (0-1 m, CHB0304; 2-4 m, LIS1038). Bubble cloud depth was defined as the depth at which the filtered profile fell below the threshold $S v$. CHB0304 profiles (left) compare calm conditions ( $\mathrm{U}_{10}<10$ th percentile) and high-wind conditions during Hurricane Isabel (2003). LIS1038 profiles (right) are during calm conditions.

An example of the time-series representation of the threshold depth is shown for station CHB0304 in Figure 3. Profiles where the shallowest bin was not above the threshold and profiles that were not continuously decreasing between the surface and threshold depth, i.e., contaminated by zooplankton or sediment, were excluded. Subsamples comprising at least $10 \%$ of the data at each station were visually inspected to confirm the absence of systematic error in raw and processed data. Infrequent anomalies $(<1 \%)$ were observed in single-beam backscatter profiles but these data could not be distinguished as either contamination (e.g., fish or boats) or relevant physical processes (e.g., boils or windrows) and were not removed due to their negligible impact.

Current speed and direction for each ensemble were extracted from two bins below the threshold depth. This method allowed for the closest approximation of surface currents while presumably scaling with the wave height such that no pings would be contaminated by wave troughs over the ensemble period. Side-lobe interference could only be reduced in the backscatter data and this '2-bin' method ensured that current speed data were well below the side-lobe contamination depth for all beams at all stations. Signal processing and statistical analyses were performed in MATLAB R2012b. 
Table 2. ADCP configuration and parameter statistics. Current velocity is the average of the daily mean and maximum values over the deployment period. All others averages are based on hourly data.

\begin{tabular}{|c|c|c|c|c|c|c|c|c|}
\hline Station & $\begin{array}{c}\text { Frequency } \\
\qquad \mathbf{k H z}\end{array}$ & $\begin{array}{c}\text { Bin Size } \\
\text { m }\end{array}$ & $\begin{array}{c}\text { Depth: } \mu \\
\text { m }\end{array}$ & $\begin{array}{c}\mathrm{U}_{10}: \mu(\sigma) \\
\mathrm{m} \mathrm{s}^{-1}\end{array}$ & $\begin{array}{c}\text { Fetch: } \mu \text { (range) } \\
\text { km }\end{array}$ & $\begin{array}{c}\text { Current: } \mu(\max ) \\
\mathrm{m} \mathrm{s}^{-1}\end{array}$ & Begin Date & End Date \\
\hline BOS1106 & 600 & 1 & 16.5 & $4.4(1.9)$ & $16(1-25)$ & $0.15(0.40)$ & $14 / 5 / 2011$ & $21 / 6 / 2011$ \\
\hline BOS1108 & 600 & 1 & 11.9 & $4.4(1.9)$ & $13(2-25)$ & $0.35(0.82)$ & $14 / 5 / 2011$ & $21 / 6 / 2011$ \\
\hline BOS1111 & 600 & 1 & 19.1 & $4.3(1.9)$ & $11(1-25)$ & $0.44(0.82)$ & $14 / 5 / 2011$ & $10 / 8 / 2011$ \\
\hline BOS1112 & 1200 & 0.5 & 13.1 & $4.2(1.8)$ & $3(1-10)$ & $0.25(0.64)$ & $28 / 6 / 2010$ & $4 / 8 / 2010$ \\
\hline BOS1115 & 600 & 1 & 12.2 & $4.2(1.8)$ & $1(0-6)$ & $0.13(0.35)$ & $28 / 6 / 2010$ & $4 / 8 / 2010$ \\
\hline CHB0301 & 1200 & 0.35 & 8.2 & $4.2(2.4)$ & $14(3-25)$ & $0.20(0.56)$ & $9 / 10 / 2002$ & $9 / 1 / 2003$ \\
\hline CHB0302 & 1200 & 0.35 & 9.1 & $4.0(2.3)$ & $13(4-25)$ & $0.20(0.59)$ & $22 / 1 / 2003$ & $2 / 5 / 2003$ \\
\hline CHB0304 & 1200 & 0.35 & 7.5 & $3.2(2.3)$ & $12(3-25)$ & $0.21(0.51)$ & $29 / 7 / 2003$ & $21 / 9 / 2003$ \\
\hline CHB0305 & 1200 & 0.35 & 7.5 & $3.9(2.4)$ & $16(3-25)$ & $0.18(0.46)$ & $10 / 10 / 2003$ & $14 / 1 / 2004$ \\
\hline CHB9903 & 300 & 1 & 23.2 & $4.5(2.3)$ & $13(1-25)$ & $0.55(1.27)$ & 21/5/1999 & 22/7/1999 \\
\hline CHB9905 & 300 & 1 & 17.1 & $4.8(3.6)$ & $3(0-14)$ & $0.21(0.59)$ & 21/5/1999 & 22/7/1999 \\
\hline FEB1102 & 600 & 1 & 14.2 & $3.8(2.3)$ & $13(0-25)$ & $0.81(1.54)$ & 29/7/1999 & $5 / 10 / 1999$ \\
\hline FEB1103 & 600 & 1 & 16.1 & $3.7(2.4)$ & $3(0-25)$ & $0.45(0.98)$ & $3 / 11 / 2011$ & $17 / 12 / 2011$ \\
\hline FEB1107 & 1200 & 0.5 & 7.6 & $3.8(2.5)$ & $1(0-2)$ & $0.32(0.58)$ & $3 / 11 / 2011$ & $17 / 12 / 2011$ \\
\hline FEB1108 & 600 & 1 & 13.1 & $3.7(2.2)$ & $20(3-25)$ & $0.39(1.29)$ & $3 / 11 / 2011$ & $17 / 12 / 2011$ \\
\hline FPI0902 & 600 & 1 & 7.9 & $2.8(2.2)$ & $1(0-25)$ & $0.61(1.19)$ & $3 / 11 / 2011$ & $17 / 12 / 2011$ \\
\hline HUR0401 & 1200 & 0.5 & 7.9 & $4.3(1.8)$ & $3(1-14)$ & $0.31(0.89)$ & $14 / 11 / 2008$ & $14 / 1 / 2009$ \\
\hline HUR0503 & 600 & 1 & 30.0 & $3.9(1.7)$ & $2(0-16)$ & $0.39(0.91)$ & $8 / 6 / 2004$ & $28 / 7 / 2004$ \\
\hline LIS1011 & 300 & 2 & 47.3 & $4.0(2.5)$ & $16(4-25)$ & $0.64(1.37)$ & $6 / 7 / 2005$ & $26 / 8 / 2005$ \\
\hline LIS1012 & 300 & 2 & 57.9 & $4.0(2.5)$ & $13(1-25)$ & $0.74(1.80)$ & $27 / 4 / 2010$ & $8 / 6 / 2010$ \\
\hline LIS1013 & 1200 & 0.5 & 7.6 & $4.0(2.5)$ & $14(1-25)$ & $0.47(1.04)$ & $27 / 4 / 2010$ & $8 / 6 / 2010$ \\
\hline LIS1018 & 600 & 1 & 20.0 & $3.4(1.7)$ & $17(10-25)$ & $0.50(1.05)$ & $27 / 4 / 2010$ & $8 / 6 / 2010$ \\
\hline LIS1021 & 600 & 1 & 26.0 & $2.7(1.8)$ & $20(11-25)$ & $0.26(0.59)$ & $10 / 6 / 2010$ & $27 / 7 / 2010$ \\
\hline LIS1023 & 600 & 1 & 12.0 & $2.3(1.6)$ & $17(1-25)$ & $0.19(0.50)$ & $10 / 6 / 2010$ & $27 / 7 / 2010$ \\
\hline LIS1027 & 300 & 2 & 43.3 & $3.7(2.1)$ & $16(5-25)$ & $0.26(0.66)$ & $10 / 6 / 2010$ & $27 / 7 / 2010$ \\
\hline LIS1029 & 1200 & 0.5 & 10.7 & $3.6(2.1)$ & $17(3-25)$ & $0.16(0.44)$ & $28 / 7 / 2010$ & $1 / 9 / 2010$ \\
\hline LIS1032 & 600 & 1 & 31.0 & $3.7(2.1)$ & $13(5-25)$ & $0.24(0.60)$ & $28 / 7 / 2010$ & 1/9/2010 \\
\hline LIS1035 & 600 & 1 & 18.3 & $4.0(1.9)$ & $9(3-25)$ & $0.15(0.39)$ & $28 / 7 / 2010$ & $1 / 9 / 2010$ \\
\hline LIS1038 & 600 & 1 & 18.9 & $4.5(2.1)$ & $2(0-21)$ & $0.32(1.41)$ & $28 / 7 / 2010$ & 1/9/2010 \\
\hline MOB1104 & 1200 & 0.5 & 4.6 & $6.2(3.2)$ & $20(5-25)$ & $0.22(0.48)$ & $28 / 7 / 2010$ & $1 / 9 / 2010$ \\
\hline MOB1105 & 1200 & 0.5 & 4.6 & $5.9(3.2)$ & $19(2-25)$ & $0.27(0.57)$ & $7 / 12 / 2010$ & $6 / 2 / 2011$ \\
\hline MOB1106 & 1200 & 0.5 & 5.1 & $6.2(3.2)$ & $12(0-25)$ & $0.57(1.13)$ & $7 / 12 / 2010$ & $6 / 2 / 2011$ \\
\hline PIR0701 & 600 & 1 & 15.5 & $3.3(1.8)$ & $8(1-25)$ & $0.40(0.89)$ & $7 / 12 / 2010$ & $6 / 2 / 2011$ \\
\hline PIR0709 & 600 & 1 & 12.8 & $3.0(1.9)$ & $1(0-3)$ & $1.04(1.79)$ & $9 / 5 / 2007$ & $1 / 8 / 2007$ \\
\hline PIR0711 & 600 & 0.5 & 8.0 & $3.0(1.9)$ & $1(0-5)$ & $0.75(1.12)$ & $21 / 6 / 2007$ & $25 / 9 / 2007$ \\
\hline SAB0803 & 600 & 1 & 13.0 & $3.9(2.7)$ & $3(0-25)$ & $0.57(1.27)$ & $21 / 6 / 2007$ & $1 / 8 / 2007$ \\
\hline SAB0805 & 1200 & 0.5 & 10.6 & $3.9(2.7)$ & $1(1-3)$ & $0.17(0.49)$ & $10 / 1 / 2010$ & $1 / 3 / 2008$ \\
\hline SAB0806 & 600 & 1 & 12.3 & $3.9(2.7)$ & $2(0-8)$ & $0.21(0.48)$ & $10 / 1 / 2010$ & $1 / 3 / 2008$ \\
\hline SAB0807 & 600 & 1 & 12.7 & $3.9(2.7)$ & $4(1-7)$ & $0.19(0.49)$ & $10 / 1 / 2010$ & $1 / 3 / 2008$ \\
\hline SAB0809 & 600 & 1 & 11.7 & $3.9(2.7)$ & $3(1-9)$ & $0.19(0.47)$ & $10 / 1 / 2010$ & $1 / 3 / 2008$ \\
\hline
\end{tabular}




\subsection{Meteorological Observations}

Hourly winds at each ADCP location were estimated using data from the nearest National Climatic Data Center meteorological [59] or National Data Buoy Center [60] meteorological station. All wind speeds were scaled to a height of $10 \mathrm{~m}\left(\mathrm{U}_{10}\right)$ following Large and Pond [61]. Fetch estimates for each station were determined in ArcGIS 10.1 using the NOAA Medium Resolution Digital Vector Shoreline dataset [62]. Lines were projected from each station on $10^{\circ}$ intervals to correspond with wind vector resolution, and each line terminated where it intersected with the shoreline (Figure 1). Fetch was defined by the orthodromic length of each line in the respective direction with a maximum value set at $25 \mathrm{~km}$.

Bubble depths and current vectors were averaged hourly to align with wind data and reduce the effect of anomalies that were not removed by prior processing. To prevent unequal weighting, hourly intervals were removed entirely if $>20 \%$ of the ensembles had been previously flagged. Current velocities relative to the wind direction were derived from the hourly current vector with positive values indicating along-wind currents and negative values indicating opposing currents. Absolute current velocities were all positive to prevent bias resulting from water quality differences between ebb and flood tides. The hourly change in the wind vector, $\Delta \mathrm{U}_{10}$, was defined as an additional environmental control related to sea state and shear generated by changing winds.

\subsection{Statistical Models}

Environmental controls on bubble depth were examined using multiple linear regression analysis. The regression model used forward-backward stepwise selection to identify first-order independent variables and interactions that significantly affected bubble depth. Selection was based on the sum of squared errors of prediction and was constrained by the Bonferroni rule. The Bonferroni rule sets the $P$-value-to-enter $<0.05 / \mathrm{q}$, where $\mathrm{q}$ is the number of predictor variables considered. This constraint allowed the full dataset to be used and ensured selection of the most parsimonious model [63]. Evaluation of model performance was based on the fit parameters of adjusted $R^{2}$ and root-mean-squared error (RMSE). Standardized coefficients and the percent variance explained were used to assess parameter sensitivity.

Regression analysis was tested on two scales of application. The 'general model' included all data from all stations, while the 'site model' was run at each station individually using data from only that site. Input parameters were $\mathrm{U}_{10}, \Delta \mathrm{U}_{10}$, current velocity $(\mathrm{CR})$, wind-relative current velocity $(\mathrm{CW})$, fetch (F), wind direction (WD), and bubble depth $\left(\mathrm{Z}_{\mathrm{b}}\right)$. For the general model, bubble depth was also represented as the fraction of water column depth $\left(\mathrm{Z}_{\mathrm{b}} / \mathrm{Z}_{0}\right)$, which ensured that the predicted depth would not exceed the total depth at shallow sites. Model performance was tested for the three scenarios shown in Table 3. CW, F, and WD were included only as the interaction terms $\mathrm{U}_{10}: \mathrm{CW}, \mathrm{U}_{10}: \mathrm{F}$, and $\mathrm{U}_{10}: \mathrm{WD}_{\text {, }}$ which represent the product of each predictor pair.

WD was functionally a site-specific, angular proxy variable that accounted for the effects of bathymetry, stratification, and the surrounding topography that were not resolved by the other variables. The angular-linear transformation of $\mathrm{U}_{10}$ :WD was nested as a non-linear regression within the model following the equations defined by SenGupta and Ugwuowo [64], Equation 3:

$$
T H_{a}=I+\sum_{i=1}^{k} \beta_{i} x_{i}+A \cos ((\omega t-\phi)+v \cos (\omega t-\phi))+\varepsilon_{i}
$$


where $I$ is the intercept, $\beta_{i}$ is the regression coefficient for predictor variable $x_{i}, A$ is the amplitude, $\omega$ is the angular frequency, $t$ is the wind direction, $\phi$ is the acrophase, $v$ is the parameter of skewness, and $\varepsilon_{i}$ is the random error component. For stations where the angular relationship was sharply peaked, e.g., due to the placement next to a man-mad structure, $v \cos (\omega t-\phi)$ was replaced by $v_{1} \sin (\omega t-\phi)$, where $v_{1}$ is the parameter of kurtosis.

Three descriptive approaches were explored as a means to pre-group stations independent of geographic location: $k$-means, hierarchical clustering, and binomial classification of mean fetch, depth, and current speed at wind speeds $<10 \mathrm{~m} \mathrm{~s}^{-1}$. Descriptive statistics of wind speed and bubble depth distributions, including the mean, standard deviation, and relevant confidence intervals were similarly investigated as a comparative index for pre- and post-analysis grouping.

Table 3. Statistical model variables.

\begin{tabular}{c|ccc}
\hline Input & & Dependent & Independent \\
\hline All data & Scenario 1 & $\mathrm{Z}_{\mathrm{b}}$ & $\mathrm{U}_{10}$ \\
(general model) & & $\mathrm{Z}_{\mathrm{b}} / \mathrm{Z}_{0}$ & $\mathrm{U}_{10}$ \\
& Scenario 2* & $\mathrm{Z}_{\mathrm{b}}$ & $\mathrm{U}_{10}, \mathrm{CR}, \mathrm{U}_{10}: \mathrm{CW}, \mathrm{U}_{10}: \mathrm{F}$ \\
& & $\mathrm{Z}_{\mathrm{b}} / \mathrm{Z}_{0}$ & $\mathrm{U}_{10}, \mathrm{CR}, \mathrm{U}_{10}: \mathrm{CW}, \mathrm{U}_{10}: \mathrm{F}$ \\
Each station & Scenario 1 & $\mathrm{Z}_{\mathrm{b}}$ & $\mathrm{U}_{10}$ \\
(site model) & Scenario 2* & $\mathrm{Z}_{\mathrm{b}}$ & $\mathrm{U}_{10}, \mathrm{CR}, \mathrm{U}_{10}: \mathrm{CW}, \mathrm{U}_{10}: \mathrm{F}$ \\
& Scenario 3* & $\mathrm{Z}_{\mathrm{b}}$ & $\mathrm{U}_{10}, \mathrm{CR}, \mathrm{U}_{10}: \mathrm{CW}, \mathrm{U}_{10}: \mathrm{WD}$ \\
\hline
\end{tabular}

$* \Delta \mathrm{U}_{10}$ excluded based on preliminary model assessment.

\section{Results}

\subsection{Bubble Depth Summary Statistics}

The nine study systems represented a broad range of estuary features with variable magnitudes of wind-driven and current-driven forcing over the deployment periods (Tables 1 and 2). Bubble depth distributions were generally similar among stations in the same system, but feature-dependent classification was otherwise highly sensitive to minor changes in selection criteria and correlated poorly with bubble depth statistics. The only consistent trend among stations was a linear decrease in bubble depth from low to moderate $\mathrm{U}_{10}$ (Figure 4). There were two exceptions to this trend: HUR0503, a deep, low-fetch station that showed no bubble entrainment over the deployment period, and PIR0701, a high-current station located in a broad coastal channel.

Bubble depth distributions were influenced predominantly by site-specific geophysical attributes rather than instrument setup or ambient noise levels. For example, $\mathrm{CHB}$ and $\mathrm{MOB}$ stations shared similar instrument configurations, deployment depths, and observed wind speeds, but bubble depth at the MOB stations showed a much stronger correlation with $U_{10}$ (Figure 4). On the other hand, large variability and some of the highest bubble depth ranges were observed at CHB and PIR despite that these stations had the lowest potential for measurement error. 

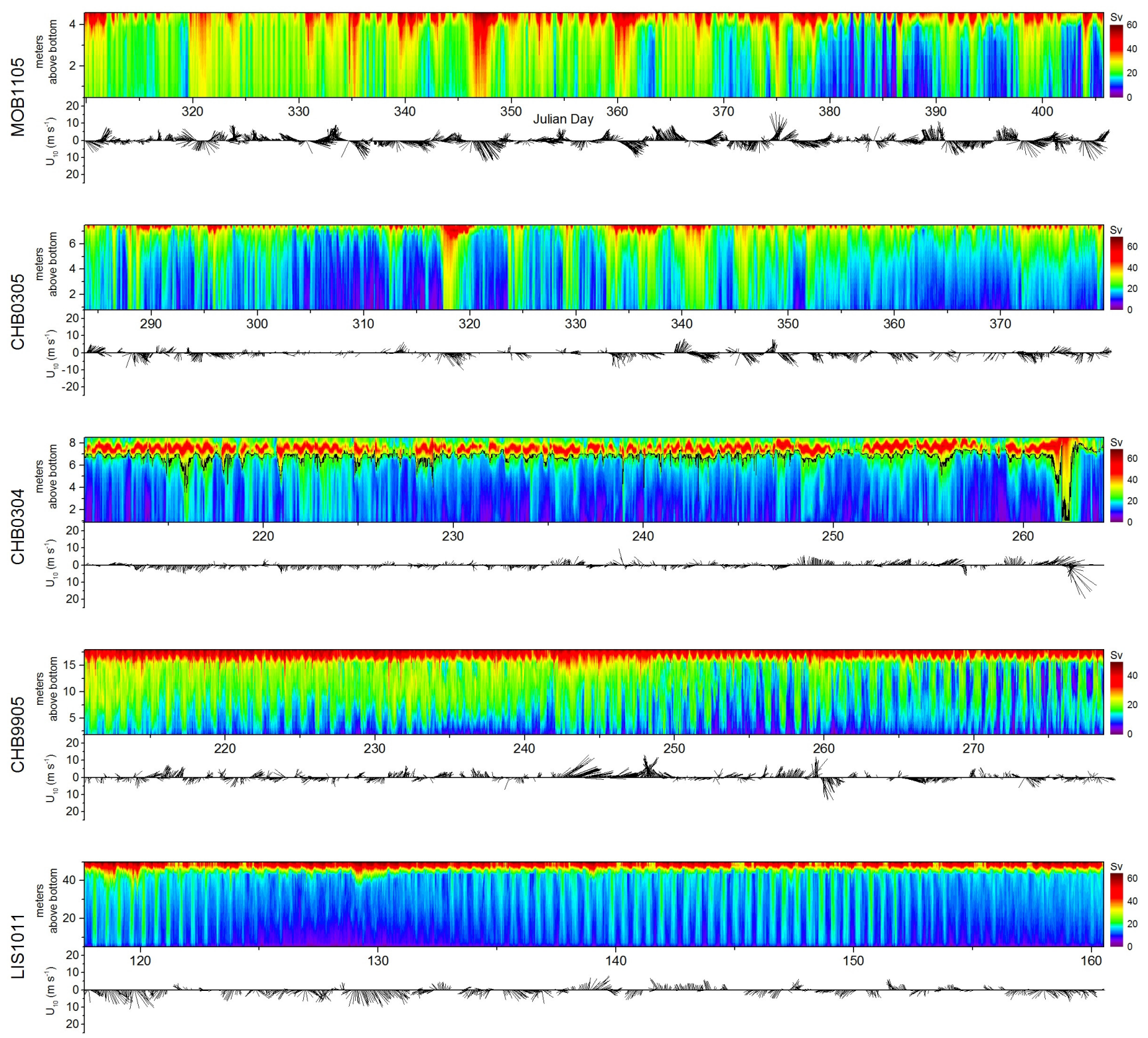

Figure 3. Backscatter time-series at stations representing varying depths (increasing from MOB1105 to LIS1011) and storm responses. Threshold depth (black line) is shown in CHB0304. Tropical cyclones: Hurricane Isabel (2003), CHB0304 Day 263; Hurricanes Dennis and Floyd (1999), CHB9905 Days 243 and 259. Frontal systems: LIS1011 Day 129, CHB0305 Days 318 and 241; MOB1105 multiple storms.

Bubble depth and distribution statistics showed low sensitivity to manual adjustment of the site-specific threshold value. This low sensitivity is consistent with prior observations in ocean studies, but background noise at most of the 41 stations was greater than reported at ocean sites $[35,48,49]$. The background noise level varied by as much as $35 \%$ between intra-system stations, e.g., within CHB and $\mathrm{SAB}$, due to either instrument configuration or spatial and temporal changes in water quality. This suggests that ADCP backscatter thresholds should be based on site-specific noise levels over the entire deployment period, as done in this study, rather than only at the time of deployment. 

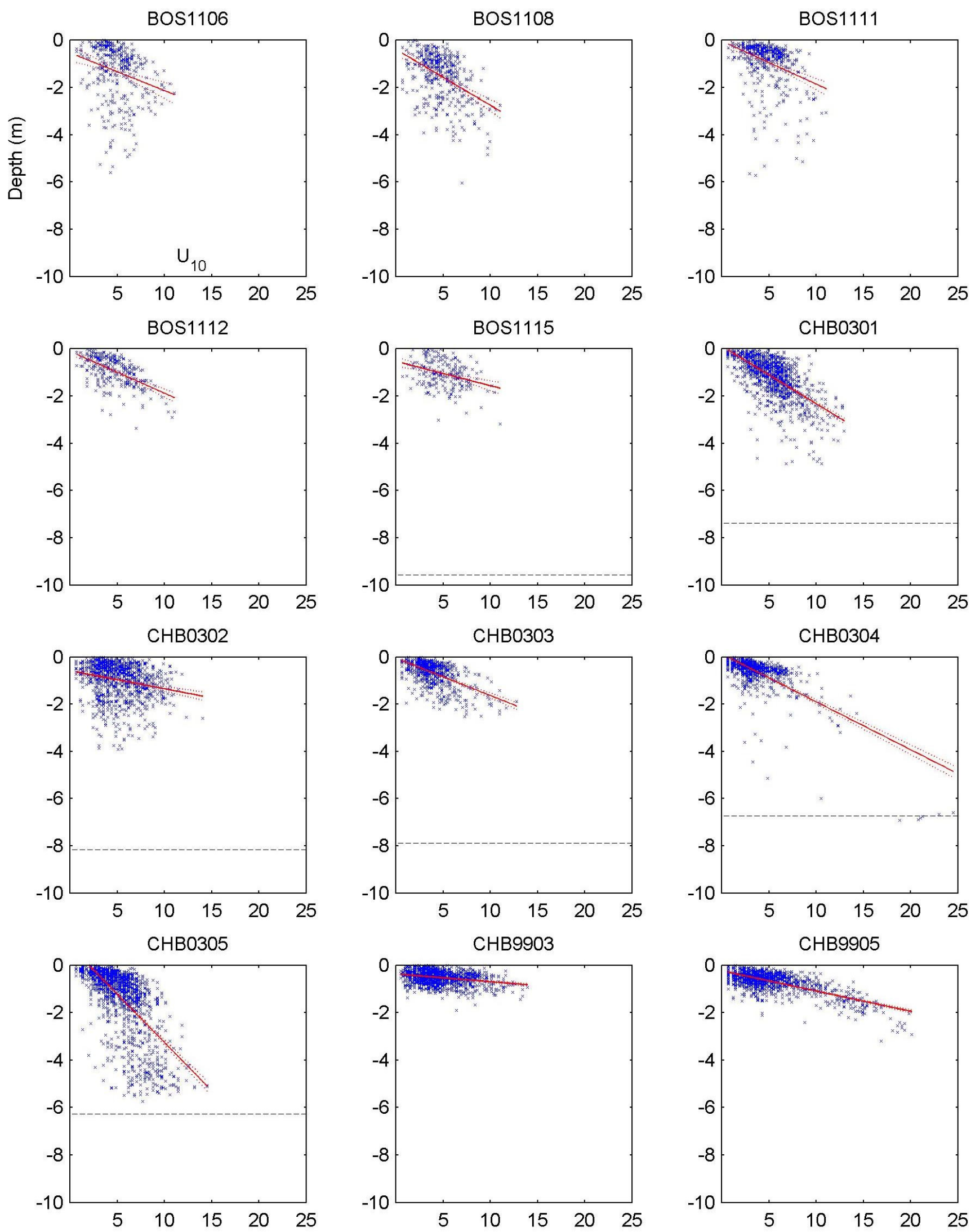

Figure 4. Cont. 

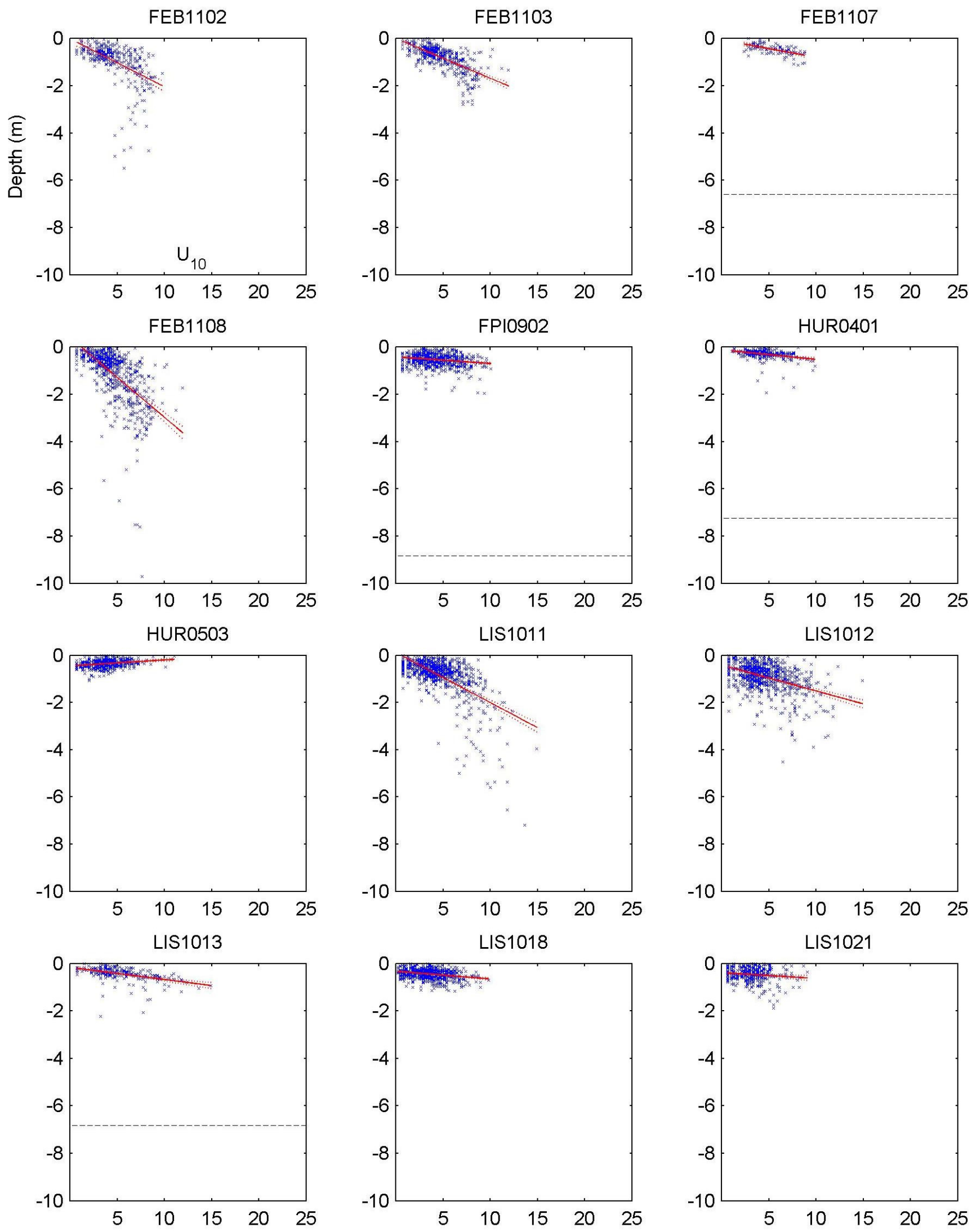

Figure 4. Cont. 

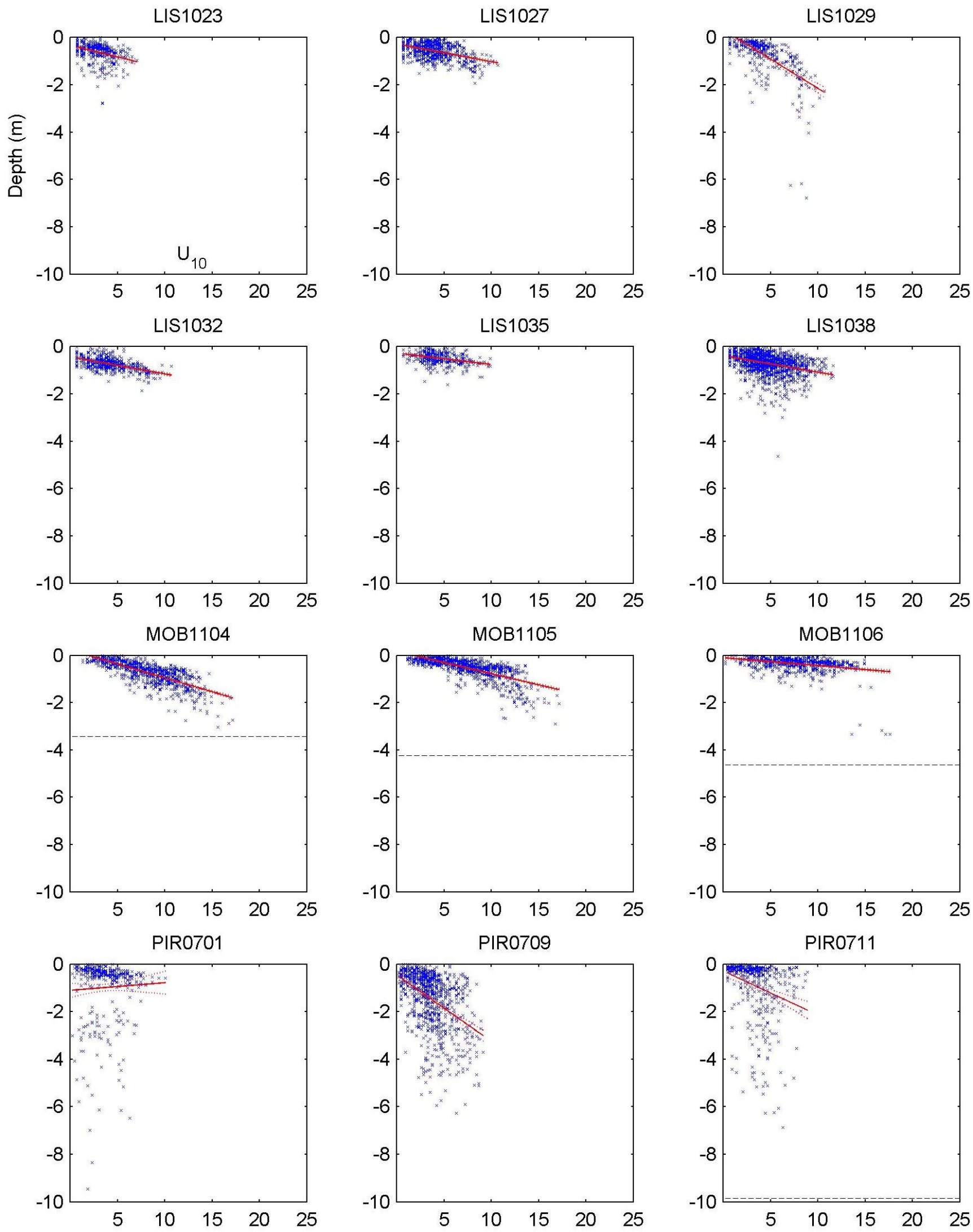

Figure 4. Cont. 

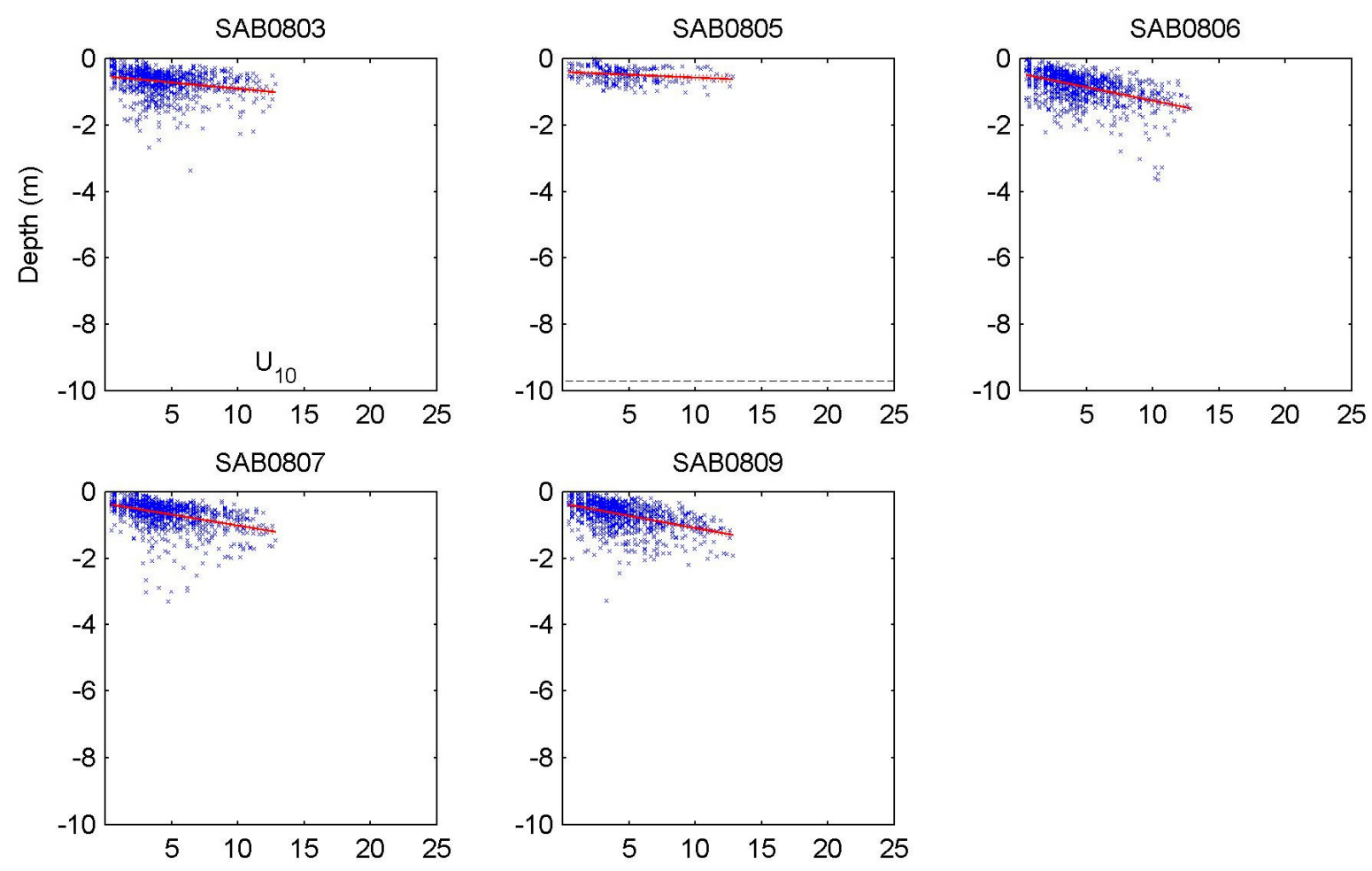

Figure 4. Hourly bubble depth $v s$. U10. Dashed line indicates average water column depth.

\subsection{Storm Events}

Several storm events occurred during ADCP deployments including Hurricane Isabel (2003) at CHB03, Hurricanes Dennis and Floyd (1999) at CHB99, and multiple strong frontal systems at LIS, $\mathrm{MOB}$, and SAB stations (Figure 3). As expected, depth and fetch appeared to a have a large influence on bubble entrainment at high winds. Bubble depths during storms were only a few meters in short-fetch areas like SAB and CHB99 stations. For example, CHB99 experienced a constant $\mathrm{U}_{10}$ between 15 and $20 \mathrm{~m} \mathrm{~s}^{-1}$ for 7 days during Hurricane Dennis (1999), but bubble depths reached no more than $3 \mathrm{~m}$ (Figure 3: Days 242-249, Figure 4). Storm-driven bubble depths were much deeper at long-fetch stations, reaching $10 \mathrm{~m}$ in the LIS and reaching the sediment at CHB03 and MOB stations (Figures 3 and 4).

The influence of wind direction on bubble plume depth was not limited to fetch alone in some estuaries. MOB and CHB03 show deep bubble entrainment during strong northeast winds and relatively less bubble entrainment during comparable winds from the south and southwest, despite large fetch in both directions (Figures 1, 3, and 4). South winds decrease density stratification in both systems and increase vertical mixing. North winds enhance stratification and deeper bubble depth would at first seem counterintuitive. However, bubble subduction and duration may be enhanced by shear turbulence from the two-directional flow, which can also influence wave steepness and breaking frequency [65].

\subsection{Regression Analysis}

Model performance data are presented in Tables S1 and S2, and parameter sensitivities are shown in Figure 5 and Tables S3 and S4. Preliminary model runs indicated that $\Delta \mathrm{U}_{10}$ was insignificant at all but a few stations and contributed little to output variability. Wave age and near-surface shear generated by 
changes in the wind vector may influence bubble distributions [66], but $\Delta \mathrm{U}_{10}$ as it was represented here was a poor predictor of bubble depth and was excluded from final model runs.

General model: Wind speed alone showed poor correlation with bubble depth under scenario 1 (Tables 3 and S1). The general model fit a larger portion of the response variation under scenario 2, which included current-based and fetch-based variables. However, the RMSE indicated that the added complexity and larger dataset did little to improve overall model prediction (Table S1). This result was not surprising given the geophysical differences among stations and the different forcing conditions observed over deployment periods (Tables 1 and 2).

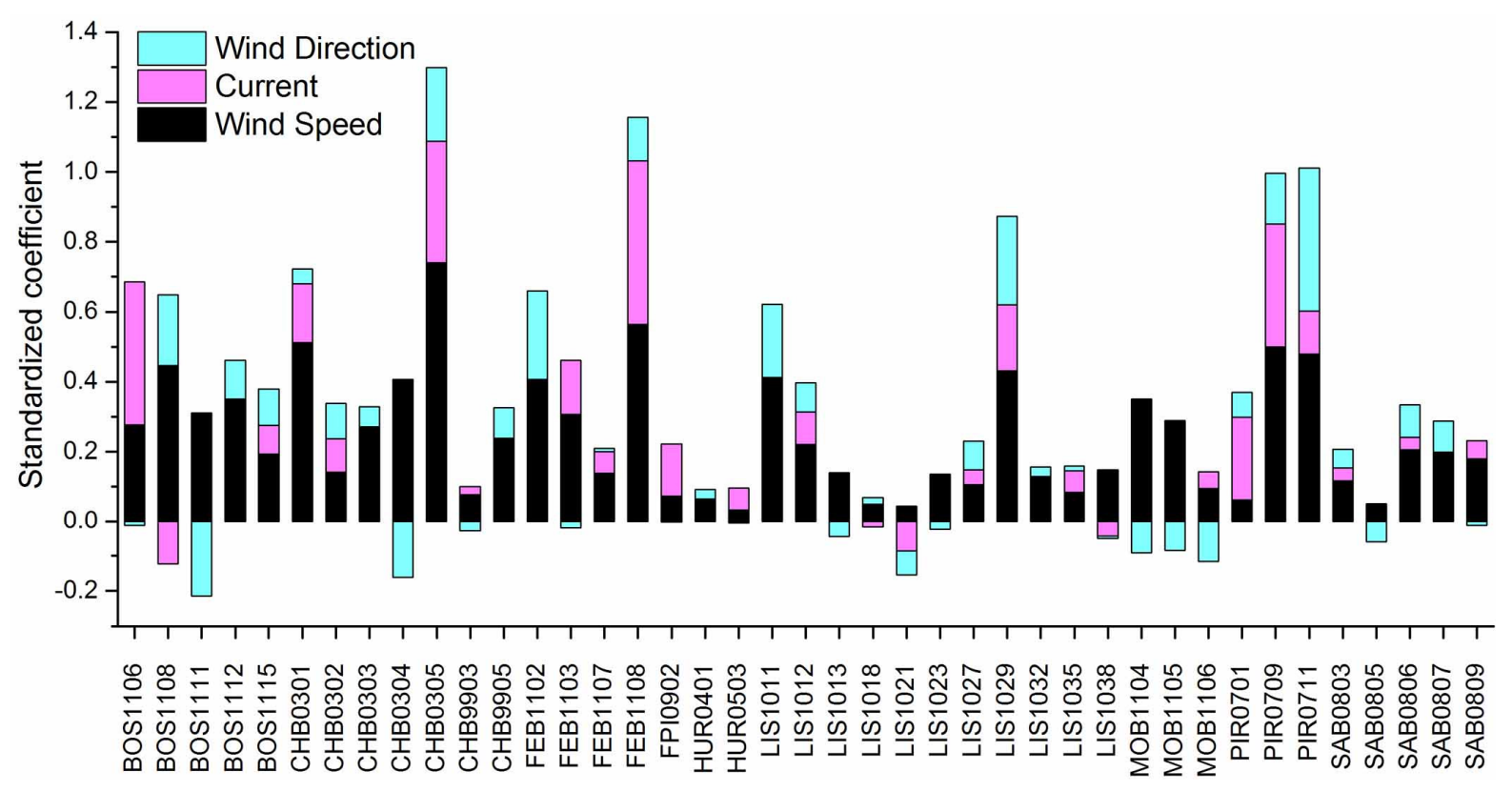

Figure 5. Sensitivity of bubble depth to wind speed ( $\left.\mathrm{U}_{10}\right)$, current velocity $(\mathrm{CR})$, and wind direction $\left(\mathrm{U}_{10}: \mathrm{WD}\right)$, represented by standardized coefficients under scenario 3 . Wind-relative current velocity (CW) was excluded, as it was insignificant at nearly all stations (Table S3).

Site model: Performance of the site model progressively increased from scenario 1 to scenario 2 and scenario 3. In this order, the model better explained the variance and reduced the RMSE at nearly every station (Table S1). Model performance was most improved under scenario 2 at several stations with high currents (FEB, FPI0902, PIR) and stations with asymmetric fetch limitation (CHB03, FEB, LIS1027, LIS1029, SAB0805). However, performance did not improve equally at all stations that met these criteria, and the parameter sensitivity could not be inferred a priori based on current speed or fetch characteristics from Tables 1 and 2. For example, LIS1011 and LIS1012 had some of the highest current speeds but were equally or more sensitive to the wind direction (Table 2, Figure 5). Under scenario 3, model performance was most improved at stations where the GIS-based fetch parameter used in scenario 2 was unable to resolve man-made structures and bathymetric influences. MOB1104, MOB1105, and SAB0803 were located near inlets that were surrounded by shallow sand bars, and several LIS and BOS stations were located near small islands and jetties. The $\mathrm{U}_{10}$ :WD parameter of scenario 3 better accounted for these features and reflected large directional sensitivity (Tables S1-S4, Figure 5). To test whether increasing the fetch resolution would improve scenario 2 predictions, fetch at station MOB1106 was manually corrected based on satellite imagery to account for nearby structures. At this higher spatial 
resolution, model performance under scenarios 2 and 3 were approximately equal. Higher-resolution fetch data were also applied to CHB03 stations, but here the improvement was negligible. CHB03 stations experience frequent stratification that is influenced by wind direction and cannot be explained by fetch alone. The deep, high-fetch stations in LIS showed the lowest overall increase in model performance and the lowest sensitivity of bubble depth to $\mathrm{U}_{10}$ (Tables S1-S4, Figure 5).

\section{Discussion}

\subsection{Geophysical Controls on Bubble Plumes}

Empirical data from diverse system types is key to understanding the physical processes that generate and shape bubble plumes. Prior analyses of in situ bubble distributions relative to wind speed are limited to a handful of studies. Thorpe [35] found a decreasing, near-linear trend for the hourly $\mathrm{U}_{10}$-bubble depth relationship at a deep (34 m), fetch-limited coastal site near Oban, UK. The study used higher resolution sampling methods ( $0.45 \mathrm{~m}$ bins sampled every 10 seconds), but the $\mathrm{U}_{10}$-bubble depth data were still highly scattered and resembled that of station LIS1012. Of the 41 stations, LIS1012 was most similar to the Oban station in terms of mean depth, fetch, and current velocity. $\mathrm{U}_{10}$-bubble depth regressions at shelf and oceanic sites have shown relatively good correlation and a well-defined $U_{10}$ threshold at which deep bubble entrainment begins [37,49,50]. LIS1011 is geomorphology similar to these open-water stations and showed a comparable $\mathrm{U}_{10}$-bubble depth relationship. The remaining 39 stations showed fewer similarities to bubble distributions observed in prior studies.

There was less bubble entrainment at the deep, long-fetch stations in the LIS relative to most other stations. A possible explanation is that wave breaking is less frequent at these stations because the wave field is able to reach a fully developed state. Shoaling of larger waves that occur in systems like LIS may also be linked to the deeper bubble depths observed at bordering shallow-water stations (LIS1029, FEB1108) [53,54]. Shallow breaking waves, known as spilling waves, appear to be the dominant wave type at stations with limited fetch, because even at high wind speeds bubble depths were less than $\sim 3 \mathrm{~m}$ (CHB99, SAB, LIS1038). These data agree with recent evidence that wave height in short-fetch waters remains constant from moderate to high winds, and only the frequency of wave breaking changes with wind speed $[52,67]$.

When comparing bubble depth distributions among stations, it is important to consider that bubble entrainment is affected by physical processes other than wave breaking alone. Studies of Langmuir circulation in lake and oceanic waters have shown that bubbles generated by a small number of breaking waves can be concentrated in convergence regions and can be subducted to depths of $>10 \mathrm{~m}[39,43,68]$. The depth and duration of bubble plumes in shallow and stratified systems can also be influenced by shear-driven turbulence that is generated at the seabed or across horizontal density surfaces [38]. It is unlikely that spilling waves can generate enough turbulence to sustain bubbles at depths far below the surface [40], and in short-fetch, high-current systems like PIR, bubble depth may closer reflect surface turbulence rather than the presence of large plunging waves. Indeed, model output confirmed that strong currents were correlated with deep entrainment of bubbles (Figures 4 and 5). However, bubble depths were generally shallower in areas where currents were high only over short distances, e.g., due to funneling through inlets or man-made structures (CHB9903, FEB1102, FPI0902, MOB1106, SAB0803). 
Deep bubble entrainment was observed in shallow, long-fetch estuaries like MOB and CHB, but was intermittent and mostly during storms (Figures 3 and 4).

\subsection{The Role of Bubbles in Air-Water $\mathrm{CO}_{2}$ Exchange}

Studies of surface-water $\mathrm{CO}_{2}$ in coastal waters have increased substantially in recent decades, but there are still relatively few gas-transfer parameterizations to choose from when estimating air-water $\mathrm{CO}_{2}$ fluxes [3,4]. Despite the paucity of gas exchange data, large variation in transfer velocities has been observed between estuaries [6,7,30-34,69]. Accordingly, it is critical to apply a parameterization that best represents the relevant geophysical controls on gas exchange. For slightly-soluble gases like $\mathrm{CO}_{2}$, air-water exchange is limited by liquid-phase transport, and injection of bubbles by breaking waves can be a highly effective means of gas exchange [70-73]. Lab and modeling studies have estimated that the contribution of bubble-mediated gas transfer scales with wind speed on the order of $\mathrm{U}_{10}{ }^{3}$ to $\mathrm{U}_{10}{ }^{6}$, while gas transfer across the unbroken water surface scales linearly with $U_{10}[14,21,22,25,26,70]$. However, bubble-mediated transport processes are complex and depend on the mechanism of bubble formation, the dynamic behavior of bubbles, and time evolution of bubble plumes. Bubbles can enhance gas exchange by increasing the air-water surface area, but also by asymmetric transfer that can supersaturate surface waters relative to the atmosphere. The main drivers of asymmetric exchange are hydrostatic pressure and surface tension, which increase the partial pressure of gas inside the bubble [70,73]. The slower the equilibration time of a bubble relative to its time evolution, the larger the effect of asymmetric transfer. Asymmetric transfer of $\mathrm{CO}_{2}$ by bubbles is much smaller than bubble-driven symmetric transfer, but it can be significant over long time scales when the concentration of $\mathrm{CO}_{2}$ in the water $\left(\mathrm{CO}_{2 \mathrm{w}}\right)$ and atmosphere $\left(\mathrm{CO}_{2 \mathrm{~atm}}\right)$ are near equilibrium [73].

Estimates of mean bubble cloud depth presented here provide only anecdotal evidence related to bubble-mediated gas exchange because of the coarse resolution of ADCP data in time and space. For example, a given backscatter signal over an hourly averaging interval could be due to deep, dense bubble plumes that are generated periodically by plunging waves. On the other hand, the same signal could equally be due to a more consistent, but less dense bubble layer sustained by water turbulence or frequent spilling waves. Bubble-mediated gas exchange under these two scenarios could be quite different, and it would therefore be impossible to quantitatively link backscatter profiles to gas exchange. Despite this, the backscatter signal indicates the presence of bubbles in either case, and model results can be used as a crude indicator of sites where bubbles are likely relevant to gas exchange.

\subsubsection{Comparison of Coastal Environments}

A recent gas tracer study by Ho et al. [11] presented one of the best spatial representations of estuarine gas transfer velocity and included concurrent ADCP measurements. The study area of Ho et al. [11] was approximately $150 \mathrm{~km}$ upstream from stations HUR0401 and HUR0502 in a narrow section of the Hudson River Estuary that is surrounded by steep topography. ADCP data from HUR and from Ho et al. [11] show an absence of wave breaking at wind speeds observed during either study period. Ho et al. [11] found one of the lowest $\mathrm{U}_{10}$-gas transfer dependencies observed in any estuary. Our data from HUR stations suggest that this low dependency may be due in part to the lack of bubble-driven gas 
exchange. Data from the other 39 stations show that HUR represents the estuary type where bubbles are least significant to $\mathrm{CO}_{2}$ fluxes.

Bubbles appeared to be a more important pathway for gas exchange in high-current or shallow, long-fetch estuaries like BOS, CHB, and PIR, where bubble entrainment was frequent and began at relatively low wind speeds (Figure 4). Statistical analysis confirmed that wind direction and current velocity can have a significant impact on bubble depth, and prior estuary studies have directly linked these parameters to gas exchange under low-to-moderate wave conditions [6,7,30-34,69]. Estuarine flux data that capture bubble-mediated gas exchange are sparse due to the inherent difficulty of sampling in rough conditions. Floating dome and gradient flux equipment that are commonly used in gas exchange studies are limited to an absence or low-frequency of breaking waves [6,30,31,69]. A few shallow-water dome studies have noted the presence of spatially-limited wave breaking [74,75]. These studies found some of the highest gas-transfer velocities yet measured, but the relative influence of wave breaking and bottom-generated turbulence could not be differentiated. Whitecap coverage has been suggested as a more practical option for estimating bubble-mediated exchange [1,14,27]. Callaghan et al. [76] found that whitecap coverage was influenced by wind speed, wind direction, tidal currents, and swell waves at a shallow coastal site exposed to the North Atlantic Ocean. Similar sensitivities were found in this study at stations with large exposure angles to the ocean (BOS1106, BOS1108, BOS1111, FEB1102, FEB1108, PIR0701), and the influence of swell may help explain the higher RMSE at these stations (Table S1). However, it should be noted that assumptions about gas exchange based on broad classification criteria are hazardous. Several methods to pre-group systems and individual stations based on geomorphology and forcing conditions from Tables 1 and 2 were tested, but no significant correlation with the observed bubble distributions was found. Instead, results have been compared in generalized terms like long- and short-fetch estuaries. This type of feature-based classification can be notoriously subjective, e.g., Table 2 [77], and a more robust method is still needed to extrapolate results to other estuaries.

\subsubsection{Ambient Water Conditions}

Scattered bubble depth distributions and different parameter sensitivities between sites may also be linked to water quality. Estuaries are often characterized by large gradients in water temperature, salinity, and the presence of surfactants, which can influence bubble plume behavior and gas exchange across the bubble surface $[14,70-72,78]$. Surfactants act as an additional surface layer through which gas must diffuse. For individual bubbles, this would reduce symmetric exchange but concurrently enhance asymmetric exchange due to the longer time required for equilibration. Surfactants also affect wave breaking and bubble plume characteristics. Asher et al. [72] showed that the presence of surfactants in a wave-breaking simulation tank decreased $\mathrm{CO}_{2}$ flux in seawater but increased $\mathrm{CO}_{2}$ flux in freshwater. The authors attributed this result to greater bubble formation in surfactant-rich freshwater, but note that the effect of surfactants on gas exchange in natural environments remains uncertain. The role of bubbles in air-water $\mathrm{CO}_{2}$ flux also depends on $\mathrm{CO}_{2} \mathrm{w}$. When $\mathrm{CO}_{2 \mathrm{w}}$ and $\mathrm{CO}_{2}$ air are near solubility equilibrium, asymmetric processes can dominate. Zhang [73] recently estimated that supersaturation of surface waters from asymmetric $\mathrm{CO}_{2}$ flux accounts for over $20 \%$ of the annual oceanic $\mathrm{CO}_{2}$ uptake. However, asymmetric processes are negligible when the difference between $\mathrm{CO}_{2 \mathrm{w}}$ and $\mathrm{CO}_{2}$ air is large. Coastal waters are highly productive and show large spatial and temporal variability in $\mathrm{CO}_{2}$, e.g., [79]. Thus, 
the most likely role of bubble-mediated gas exchange in estuaries would be to ventilate surface waters where $\mathrm{CO}_{2 \mathrm{w}}$ is driven by biological activity.

\subsubsection{Storm-Driven Fluxes}

Figure 4 illustrates how bubbles can be mixed throughout the entire water column of shallow, long-fetch estuaries during storm events. In frequently-stratified systems like $\mathrm{CHB}$, the mixture of bubbles with high- $\mathrm{CO}_{2}$ bottom water and porewater could release a substantial quantity of $\mathrm{CO}_{2}$ to the atmosphere [80]. Hence, episodic perturbations by storms can have a large impact on estuarine gas fluxes relative to the short time scales on which they occur. Anecdotal evidence from prior studies supports this hypothesis. Sediment resuspension and intense vertical mixing have been observed during several storm events in $\mathrm{CHB}$ and $\mathrm{MOB}$ [81-86]. Akulichev and Bulanov [55] found that bubbles reached the seafloor during a storm in the shallow $(10 \mathrm{~m})$ Sea of Japan and Evans et al. [87] showed that the elevated $\mathrm{CO}_{2}$ in the Columbia River Estuary, USA was almost entirely ventilated during a major storm event. Crosswell et al. [80] estimated that in a shallow, seasonally-stratified estuary, the $\mathrm{CO}_{2}$ efflux due to a single tropical cyclone (Hurricane Irene, 2011) could equal the net air-water $\mathrm{CO}_{2}$ transport over several cyclone-free years. Storm-generated bubble plumes had a smaller impact in deep or fetch-limited systems, e.g., LIS and CHB99 (Figure 4). In large, deep systems like LIS, storms may be less significant to air-water $\mathrm{CO}_{2}$ fluxes compared to the seasonal effect of convective mixing [88]. Alternatively, bubble-driven $\mathrm{CO}_{2}$ exchange may be an important component of annual $\mathrm{CO}_{2}$ fluxes in shallow systems where storms are frequent, e.g., MOB.

\section{Conclusions}

This study used acoustic methods of bubble detection developed in prior research [35,41,48-50,57] to compile one of the most extensive datasets of its kind. Collectively, these data amount to six years (2160 deployment days) of ADCP measurements that were gathered during two decades of NOAA current surveys. The dominant environmental controls on bubble entrainment were identified using statistical analysis and used to compare a diverse range of coastal environments. The inclusion of easily-measurable parameters into a site-specific regression model significantly improved model performance, whereas a widely-applicable model showed less improvement and poor overall prediction capability. When considering currently available flux data, parameterizations based on estuary features may be a better option than combining data from multiple estuary types into a single parameterization. I caution however, that system classification may not be intuitive.

The influence of wind speed, fetch, current velocity, and wind direction on bubble depth were site-specific, but general trends were observed within estuaries and between similar sites. Differences between stations were most pronounced during storms. For example, within the same $\mathrm{U}_{10}$ range, there was no detectable bubble entrainment as some sites, while bubbles were dispersed throughout the entire water column at others. It has been argued that bubbles and the forces that generate them can substantially increase $\mathrm{CO}_{2}$ exchange. If so, the different bubble distributions between estuaries may imply differences in biogeochemical cycling. The role of episodic gas exchange via bubbles appeared to be minor relative to tidal forcing in high-current estuaries and relative to seasonal forcing in deep estuaries. However, storm-driven bubble entrainment could have a much larger impact on carbon cycling 
in broad, shallow estuaries. I emphasize that these conclusions are preliminary and highly speculative, as coarse resolution of bubble depth alone can hardly be linked to gas exchange. Additionally, the effect of water quality on bubble exchange processes is not well understood, particularly at the high surfactant concentrations and variable water conditions found in estuaries. Future research efforts focused on high-resolution, multi-frequency acoustic measurements are needed to characterize bubble plume dynamics on a scale at which they occur. Gas exchange studies that capture a broader range of estuary types and forcing conditions are needed to improve estimates of bubble-mediated $\mathrm{CO}_{2}$ flux.

\section{Acknowledgments}

I thank Todd Ehret at NOAA CO-OPS for providing ADCP backscatter data, the NOAA C-MIST program for maintaining a well-organized public database, and all the unknown individuals that took part in the ADCP deployments. I thank Hans W. Paerl, Burke Hales, Michael Wetz, Stephen C. Whalen, and Michael F. Piehler for helpful discussions and I thank two anonymous reviewers for insightful comments that helped improve this manuscript. This work was supported in part by a National Science Foundation Chemical Oceanography grant (Ocean Sciences 0726989)

\section{Conflicts of Interest}

The author declares no conflict of interest.

\section{References}

1. Wanninkhof, R.; Asher, W.E.; Ho, D.T.; Sweeney, C.; McGillis, W.R. Advances in quantifying air-sea gas exchange and environmental forcing. Annu. Rev. Mar. Sci. 2009, 1, 213-244.

2. Fairall, C.; Yang, M.; Bariteau, L.; Edson, J.; Helmig, D.; McGillis, W.; Pezoa, S.; Hare, J.; Huebert, B.; Blomquist, B. Implementation of the Coupled Ocean-Atmosphere Response Experiment flux algorithm with $\mathrm{CO}_{2}$, dimethyl sulfide, and $\mathrm{O}_{3}$. J. Geophys. Res. Oceans 2011, 116, C00F09.

3. Chen, C.T.; Huang, T.H.; Chen, Y.C.; Bai, Y.; He, X.; Kang, Y. Air-Sea exchanges of $\mathrm{CO}_{2}$ in the world's coastal seas. Biogeosciences 2013, 10, 6509-6544.

4. Laruelle, G.G.; Dürr, H.H.; Lauerwald, R.; Hartmann, J.; Slomp, C.P.; Goossens, N.; Regnier, P.A.G. Global multi-scale segmentation of continental and coastal waters from the watersheds to the continental margins. Hydrol. Earth Syst. Sc. 2013, 17, 2029-2051.

5. Cai, W.J. Estuarine and Coastal Ocean Carbon Paradox: $\mathrm{CO}_{2}$ Sinks or Sites of Terrestrial Carbon Incineration? Annu. Rev. Mar. Sci. 2011, 3, 123-145.

6. Zappa, C.J.; McGillis, W.R.; Raymond, P.A.; Edson, J.B.; Hintsa, E.J.; Zemmelink, H.J.; Dacey, J.W.; Ho, D.T. Environmental turbulent mixing controls on air-water gas exchange in marine and aquatic systems. Geophys. Res. Lett. 2007, 34, L10601.

7. Alin, S.R.; Maria de Fátima, F.; Salimon, C.I.; Richey, J.E.; Holtgrieve, G.W.; Krusche, A.V.; Snidvongs, A. Physical controls on carbon dioxide transfer velocity and flux in low-gradient river systems and implications for regional carbon budgets. J. Geophys. Res. Oceans 2011, 116, G01009. 
8. Wanninkhof, R. Relationship between wind speed and gas exchange. J. Geophys. Res. Oceans 1992, 97, 7373-7382.

9. Nightingale, P.D.; Malin, G.; Law, C.S.; Watson, A.J.; Liss, P.S.; Liddicoat, M.I.; Boutin, J.; Upstill-Goddard, R.C. In situ evaluation of air-sea gas exchange parameterizations using novel conservative and volatile tracers. Global Biogeochem. Cycles 2000, 14, 373-387.

10. Raymond, P.A.; Cole, J.J. Gas exchange in rivers and estuaries: Choosing a gas transfer velocity. Estuaries Coasts 2001, 24, 312-317.

11. Ho, D.T.; Schlosser, P.; Orton, P.M. On Factors Controlling Air-Water Gas Exchange in a Large Tidal River. Estuaries Coasts 2011, 34, 1103-1116.

12. Ho, D.T.; Law, C.S.; Smith, M.J.; Schlosser, P.; Harvey, M.; Hill, P. Measurements of air-sea gas exchange at high wind speeds in the Southern Ocean: Implications for global parameterizations. Geophys. Res. Lett. 2006, 33, L16611.

13. Jiang, L.Q.; Cai, W.J.; Wang, Y. A comparative study of carbon dioxide degassing in river-and marine-dominated estuaries. Limnol. Oceanogr. 2008, 53, 2603-2615.

14. Upstill-Goddard, R.C. Air-sea gas exchange in the coastal zone. Estuar. Coast. Shelf Sci. 2006, 70, 388-404.

15. Fangohr, S.; Woolf, D.K. Application of new parameterizations of gas transfer velocity and their impact on regional and global marine $\mathrm{CO}_{2}$ budgets. J. Mar. Syst. 2007, 66, 195-203.

16. Signorini, S.R.; McClain, C.R. Effect of uncertainties in climatologic wind, ocean $\mathrm{pCO}_{2}$, and gas transfer algorithms on the estimate of global sea-air $\mathrm{CO}_{2}$ flux. Glob. Biogeochem. Cycles 2009, 23, GB2025.

17. Johnson, M.T.; Hughes, C.; Bell, T.G.; Liss, P.S. A Rumsfeldian analysis of uncertainty in air-sea gas exchange. In Gas Transfer at Water Surfaces; Kyoto University Press: Kyoto, Japan, 2011; pp. 464-485.

18. Smith, M.J.; Ho, D.T.; Law, C.S.; McGregor, J.; Popinet, S.; Schlosser, P. Uncertainties in gas exchange parameterization during the SAGE dual-tracer experiment. Deep Sea Res. Part II Top. Studies Oceanogr. 2011, 58, 869-881.

19. Stanley, R.H.; Jenkins, W.J.; Lott, D.E.; Doney, S.C. Noble gas constraints on air-sea gas exchange and bubble fluxes. J. Geophys. Res. Oceans 2009, 114, C11020.

20. de Leeuw, G.; Kunz, G.; Caulliez, G.; Woolf, D.; Bowyer, P.; Leifer, I.; Nightingale, P.; Liddicoat, M.; Rhee, T.; Andreae, M. LUMINY: An overview. In Gas Transfer at Water Surfaces; American Geophysical Union: Washington, DC, USA, 2002.

21. Liang, J.H.; McWilliams, J.C.; Sullivan, P.P.; Baschek, B. Large eddy simulation of the bubbly ocean: New insights on subsurface bubble distribution and bubble-mediated gas transfer. J. Geophys. Res. Oceans 2012, 117, C04002.

22. Liang, J.; McWilliams, J.C.; Sullivan, P.P.; Baschek, B. Modeling bubbles and dissolved gases in the ocean. J. Geophys. Res. Oceans 2011, 116, C03015.

23. Krall, K. E.; Jähne, B. First laboratory study of air-sea gas exchange at hurricane wind speeds. Ocean Sci. 2014, 10, 257-265.

24. Zhao, D.; Toba, Y.; Suzuki, Y.; Komori, S. Effect of wind waves on air-sea gas exchange: Proposal of an overall $\mathrm{CO}_{2}$ transfer velocity formula as a function of breaking-wave parameter. Tellus $B$ 2003, 55, 478-487. 
25. Woolf, D.K. Parametrization of gas transfer velocities and sea-state-dependent wave breaking. Tellus B 2005, 57, 87-94.

26. Woolf, D.; Leifer, I.; Nightingale, P.; Rhee, T.; Bowyer, P.; Caulliez, G.; De Leeuw, G.; Larsen, S.E.; Liddicoat, M.; Baker, J. Modelling of bubble-mediated gas transfer: Fundamental principles and a laboratory test. J. Mar. Syst. 2007, 66, 71-91.

27. Goddijn-Murphy, L.; Woolf, D.K.; Callaghan, A.H. Parameterizations and algorithms for oceanic whitecap coverage. J. Phys. Oceanogr. 2011, 41, 742-756.

28. Hartman, B.; Hammond, D.E. Gas exchange rates across the sediment-water and air-water interfaces in south San Francisco Bay. J. Geophys. Res. Oceans 1984, 89, 3593-3603.

29. Wanninkhof, R.; Ledwell, J.R.; Broecker, W.S.; Hamilton, M. Gas exchange on Mono lake and Crowley lake, California. J. Geophys. Res. Oceans 1987, 92, 14567-14580.

30. Borges, A.V.; Vanderborght, J.P.; Schiettecatte, L.S.; Gazeau, F.; Ferrón-Smith, S.; Delille, B.; Frankignoulle, M. Variability of the gas transfer velocity of $\mathrm{CO}_{2}$ in a macrotidal estuary (the Scheldt). Estuaries Coasts 2004, 27, 593-603.

31. Borges, A.; Delille, B.; Schiettecatte, L.; Gazeau, F.; Abril, G.; Frankignoulle, M. Gas transfer velocities of $\mathrm{CO}_{2}$ in three European estuaries (Randers Fjord, Scheldt and Thames). Limnol. Oceanogr. 2004, 49, 1630-1641.

32. Abril, G.; Commarieu, M.; Sottolichio, A.; Bretel, P.; Guerin, F. Turbidity limits gas exchange in a large macrotidal estuary. Estuar. Coast. Shelf Sci. 2009, 83, 342-348.

33. Orton, P.M.; McGillis, W.R.; Zappa, C.J. Sea breeze forcing of estuary turbulence and air-water $\mathrm{CO}_{2}$ exchange. Geophys. Res. Lett. 2010, 37, L13603.

34. Orton, P.M.; Zappa, C.J.; McGillis, W.R. Tidal and atmospheric influences on near-surface turbulence in an estuary. J. Geophys. Res. Oceans 2010, 115, C12029.

35. Thorpe, S. On the Clouds of Bubbles Formed by Breaking Wind-Waves in Deep Water, and their Role in Air-Sea Gas Transfer. Philos. Trans. R. Soc. Lond. A Math. Phys. Eng. Sci. 1982, 304, $155-210$.

36. Thorpe, S. On the determination of $\mathrm{Kv}$ in the near-surface ocean from acoustic measurements of bubbles. J. Phys. Oceanogr. 1984, 14, 855-863.

37. Thorpe, S. Measurements with an automatically recording inverted echo sounder; ARIES and the bubble clouds. J. Phys. Oceanogr. 1986, 16, 1462-1478.

38. Thorpe, S. Langmuir circulation. Annu. Rev. Fluid Mech. 2004, 36, 55-79.

39. Thorpe, S.; Osborn, T.; Farmer, D.; Vagle, S. Bubble clouds and Langmuir circulation: Observations and models. J. Phys. Oceanogr. 2003, 33, 2013-2031.

40. Thorpe, S.; Ulloa, M.; Baldwin, D.; Hall, A. An autonomously recording inverted echo sounder: ARIES II. J. Atmos. Ocean. Technol. 1998, 15, 1346-1360.

41. Zedel, L. Deep ocean wave measurements using a vertically oriented sonar. J. Atmos. Ocean. Technol. 1994, 11, 182.

42. Zedel, L. Using ADCP background sound levels to estimate wind speed. J. Atmos. Ocean. Technol. 2001, 18, 1867-1881.

43. Zedel, L.; Farmer, D. Organized structures in subsurface bubble clouds: Langmuir circulation in the open ocean. J. Geophys. Res. Oceans 1991, 96, 8889-8900. 
44. Vagle, S.; Farmer, D.M. The measurement of bubble-size distributions by acoustical backscatter. J. Atmos. Ocean. Technol. 1992, 9, 630-644.

45. Brown, J.; Barton, E.D.; Trasviña, A.; Vélez, H.S.; Kosro, P.M.; Smith, R.L. Estimation of surface winds from upward looking acoustic Doppler current profilers. J. Geophys. Res. Oceans 1992, 97, 17925-17930.

46. Visbeck, M.; Fischer, J. Sea surface conditions remotely sensed by upward-looking ADCPs. J. Atmos. Ocean. Technol. 1995, 12, 141-149.

47. Terrill, E.J.; Melville, W.K.; Stramski, D. Bubble entrainment by breaking waves and their influence on optical scattering in the upper ocean. J. Geophys. Res. Oceans 2001, 106, 16815-16823.

48. Trevorrow, M.V. Measurements of near-surface bubble plumes in the open ocean with implications for high-frequency sonar performance. J. Acoust. Soc. Am. 2003, 114, 2672-2684.

49. Vagle, S.; McNeil, C.; Steiner, N. Upper ocean bubble measurements from the NE Pacific and estimates of their role in air-sea gas transfer of the weakly soluble gases nitrogen and oxygen. J. Geophys. Res. Oceans 2010, 115, C12054.

50. Wang, D.; Wijesekera, H.; Teague, W.; Rogers, W.; Jarosz, E. Bubble cloud depth under a hurricane. Geophys. Res. Lett. 2011, 38, L14604.

51. Lamarre, E.; Melville, W. Void-fraction measurements and sound-speed fields in bubble plumes generated by breaking waves. J. Acoust. Soc. Am. 1994, 95, 1317.

52. Anguelova, M.D.; Huq, P. Characteristics of bubble clouds at various wind speeds. J. Geophys. Res. Oceans 2012, 117, C03036.

53. Blenkinsopp, C.; Chaplin, J. Void fraction measurements in breaking waves. Proc. R. Soc. A Math. Phys. Eng. Sci. 2007, 463, 3151-3170.

54. Blenkinsopp, C.; Chaplin, J. Void fraction measurements and scale effects in breaking waves in freshwater and seawater. Coast. Eng. 2011, 58, 417-428.

55. Akulichev, V.A.; Bulanov, V.A. Measurements of bubbles in sea water by nonstationary sound scattering. J. Acoust. Soc. Am. 2011, 130, 3438-3449.

56. NOAA's Currents Measurements Interface for the Study of Tides. Available online: https://cmist.noaa.gov/cmist (accessed on 15 January 2013).

57. Gostiaux, L.; van Haren, H. Extracting meaningful information from uncalibrated backscattered echo intensity data. J. Atmos. Ocean. Technol. 2010, 27, 943-949.

58. Rossby, T.; Flagg, C.; Ortner, P.; Hu, C. A tale of two eddies: Diagnosing coherent eddies through acoustic remote sensing. J. Geophys. Res. Oceans 2011, 116, C12017.

59. NOAA's National Climate Data Center. Available online: http://www.ncdc.noaa.gov (accessed on 1 February 2013).

60. NOAA's National Data Buoy Center. Available online: http://www.ndbc.noaa.gov (accessed on 1 February 2013).

61. Large, W.; Pond, S. Open ocean momentum flux measurements in moderate to strong winds. J. Phys. Oceanogr. 1981, 11, 324-336.

62. NOAA Shoreline Website. Available online: http://shoreline.noaa.gov (accessed on 15 February 2013).

63. Westfall, P.H.; Tobias, R.R.D.; Wolfinger, R.D. Multiple comparisons and multiple tests using SAS; SAS Institute: Cary, NC. USA, 2011. 
64. SenGupta, A.; Ugwuowo, F.I. Asymmetric circular-linear multivariate regression models with applications to environmental data. Environ. Ecol. Stat. 2006, 13, 299-309.

65. Jia, P.; Li, M. Dynamics of wind-driven circulation in a shallow lagoon with strong horizontal density gradient. J. Geophys. Res. Oceans 2012, 117, C05013.

66. Callaghan, A.; de Leeuw, G.; Cohen, L.; O’Dowd, C.D. Relationship of oceanic whitecap coverage to wind speed and wind history. Geophys. Res. Lett. 2008, 35, L23609.

67. Caulliez, G. Wind wave breaking from micro to macroscale. In Gas Transfer at Water Surface; Kyoto University Press: Kyoto, Japan, 2011; pp. 151-163.

68. Sullivan, P.P.; McWilliams, J.C. Dynamics of winds and currents coupled to surface waves. Annu. Rev. Fluid Mech. 2010, 42, 19-42.

69. Zappa, C.J.; Raymond, P.A.; Terray, E.A.; McGillis, W.R. Variation in surface turbulence and the gas transfer velocity over a tidal cycle in a macro-tidal estuary. Estuaries 2003, 26, 1401-1415.

70. Memery, L.; Merlivat, L. Modelling of gas flux through bubbles at the air-water interface. Tellus B 1985, 37, 272-285.

71. Asher, W.E.; Karle, L.M.; Higgins, B.J.; Farley, P.J.; Monahan, E.C.; Leifer, I.S. The influence of bubble plumes on air-seawater gas transfer velocities. J. Geophys. Res. Oceans 1996, 101, 12027-12041.

72. Asher, W.E.; Karle, L.M.; Higgins, B.J. On the differences between bubble-mediated air-water transfer in freshwater and seawater. J. Mar. Res. 1997, 55, 813-845.

73. Zhang, $\mathrm{X}$. Contribution to the global air-sea $\mathrm{CO}_{2}$ exchange budget from asymmetric bubble-mediated gas transfer. Tellus B 2012, 64, 17260.

74. Tokoro, T.; Watanabe, A.; Kayanne, H.; Nadaoka, K.; Tamura, H.; Nozaki, K.; Kato, K.; Negishi, A. Measurement of air-water $\mathrm{CO}_{2}$ transfer at four coastal sites using a chamber method. J. Mar. Syst. 2007, 66, 140-149.

75. Abe, O.; Watanabe, A.; Sarma, V.; Matsui, Y.; Yamano, H.; Yoshida, N.; Saino, T. Air-sea gas transfer in a shallow, flowing and coastal environment estimated by dissolved inorganic carbon and dissolved oxygen analyses. J. Oceanogr. 2010, 66, 363-372.

76. Callaghan, A.H.; Deane, G.B.; Stokes, M.D. Observed physical and environmental causes of scatter in whitecap coverage values in a fetch-limited coastal zone. J. Geophys. Res. Oceans 2008, 113, C05022.

77. Elliott, M.; McLusky, D.S. The need for definitions in understanding estuaries. Estuar. Coast. Shelf Sci. 2002, 55, 815-827.

78. Callaghan, A.H.; Deane, G.B.; Stokes, M.D. Two regimes of laboratory whitecap foam decay: Bubble-plume controlled and surfactant stabilized. J. Phys. Oceanogr. 2013, 43, 1114-1126.

79. Crosswell, J.R.; Wetz, M.S.; Hales, B.; Paerl, H.W. Air-water $\mathrm{CO}_{2}$ fluxes in the microtidal Neuse River Estuary, North Carolina. J. Geophys. Res. Oceans 2012, 117, C08017.

80. Crosswell, J.R.; Wetz, M.S.; Hales, B.; Paerl, H.W. Extensive $\mathrm{CO}_{2}$ emissions from shallow coastal waters during passage of Hurricane Irene (August 2011) over the Mid-Atlantic Coast of the USA. Limnol. Oceanogr. 2014, 59, 1651-1665. 
81. Brasseur, L.; Trembanis, A.; Brubaker, J.; Friedrichs, C.; Nelson, T.; Wright, L.; Reay, W.; Haas, L.; Sellner, K. Physical response of the York River estuary to Hurricane Isabel. In Hurricane Isabel in Perspective, Chesapeake Research Consortium; CRC Publication: Edgewater, MD, USA, 2005; Volume 5, pp. 57-64.

82. Li, M.; Zhong, L.; Boicourt, W.C.; Zhang, S.; Zhang, D. Hurricane-induced storm surges, currents and destratification in a semi-enclosed bay. Geophys. Res. Lett. 2006, 33, L02604.

83. Gong, W.; Shen, J.; Reay, W.G. The hydrodynamic response of the York River estuary to Tropical Cyclone Isabel, 2003. Estuar. Coast. Shelf Sci. 2007, 73, 695-710.

84. Ha, H.; Maa, J.; Park, K.; Kim, Y. Estimation of high-resolution sediment concentration profiles in bottom boundary layer using pulse-coherent acoustic Doppler current profilers. Mar. Geol. 2011, 279, 199-209.

85. Cho, K.; Wang, H.V.; Shen, J.; Valle-Levinson, A.; Teng, Y. A modeling study on the response of Chesapeake Bay to hurricane events of Floyd and Isabel. Ocean Modelling 2012, 49, 22-46.

86. Ha, H.K.; Park, K. High-resolution comparison of sediment dynamics under different forcing conditions in the bottom boundary layer of a shallow, micro-tidal estuary. J. Geophys. Res. Oceans 2012, 117, C06020.

87. Evans, W.; Hales, B.; Strutton, P.G. $\mathrm{pCO}_{2}$ distributions and air-water $\mathrm{CO}_{2}$ fluxes in the Columbia River estuary. Estuar. Coast. Shelf Sci. 2013, 117, 260-272.

88. Welsh, B.L.; Eller, F.C. Mechanisms controlling summertime oxygen depletion in western Long Island Sound. Estuaries 1991, 14, 265-278.

(C) 2015 by the authors; licensee MDPI, Basel, Switzerland. This article is an open access article distributed under the terms and conditions of the Creative Commons Attribution license (http://creativecommons.org/licenses/by/4.0/). 